\title{
NOTAS ADICIONAIS SOBRE OS RITMITOS DE ITU, PALEOZÓICO SUPERIOR DA BACIA DO PARANÁ, SÃO PAULO
}

\author{
Setembrino Petri*
}

\author{
RESUMO
}

\begin{abstract}
O objetivo do presente artigo é apresentar dados adicionais sobre o litossoma "varvito de Itu', obtidos pelo aprofundamento do poço IG-IT 1/85 até o embasamento cristalino e através de considerações sobre um poço perfurado no sítio São José, a cerca de $2 \mathrm{~km}$ a SSW da cidade de Itu.

Foi possível, por estes dados, reavaliar a extensão do "lago varvito de Itu", que se estenderia por $8 \mathrm{~km}$ na direção E-W e $9 \mathrm{~km}$ na direção $\mathrm{N}-\mathrm{S}$, podendo eventualmente estender-se por distância maior.

Verificou-se, além disso, a extensa ocorrência de um diamictito com granodecrescência ascendente, em contato direto com embasamento cristalino.
\end{abstract}

\begin{abstract}
This paper deals with the classical Carboniferous lithosome "varvito de Itu", developed in the region, State of São Paulo, Brazil. New data about this lithosome as well as its relationship to other ones, were pointed out by the study of the lithological cores of the well IG-IT 1/85 and the study of the lithological description of an older well drilled at São José locality, $2 \mathrm{~km}$ SSW from the city of Itu.

As the result of these studies, the assumed minimum geographical extension of the "varvito de Itu lake"' is enlarged to an EW $8 \mathrm{~km}$ to a M-S $9 \mathrm{~km}$. It is also stressed in this paper the widespread presence, in the region, of a fining upward diamictite resting on the crystalline basement.
\end{abstract}

\section{NOVOS DADOS}

Neste artigo completam-se os dados publicados por PETRI (1985). No ano de 1985, o poço IG-IT $1 / 85$ (vide PETRI, op. cit. fig. 1, para a localização deste poço) tinha sido interrompido a $243 \mathrm{~m}$ de profundidade. Em 1986 a perfuração foi retomada e chegou-se ao embasamento cristalino, a $261,5 \mathrm{~m}$. De acordo com o Dr. Ruy Osório de Freitas (comunicação verbal), que teve a gentileza de estudar secção delgada da rocha do embasamento, trata-se de um gnais de injeção cataclástica. Aqui deixamos nossos agradecimentos ao Dr. Freitas.

As únicas sondagens que atravessaram o litossoma "varvito de Itu" e atingiram o embasamento, na região de Itu, e que possuem razoável descrição de suas litologias, foram quatro na área de Schincariol (MEZZALIRA, 1969; PETRI, 1985), duas no sítio São José
(MEZZALIRA, 1980) e o poço IG-IT 1/85 (PETRI, 1985).

Infelizmente faltam as localizações geográficas precisas das sondagens do sítio São José. MEZZALIRA (1980) as situa na Granja Santa Rosa a $2 \mathrm{~km}$ a SSW da cidade de Itu. Como o poço n. ${ }^{\circ}$ 2 desta localidade se inicia à cota de $600 \mathrm{~m}$, ele estaria próximo à sede do sítio São José (como aparece na folha SF $23-\mathrm{Y}-\mathrm{C}-11-3,1: 50000$ do IBGE, o que o colocaria exatamente à SE da pedreira clássica de varvito de Itu, onde o topo do varvito também está a $600 \mathrm{~m}$. A linha que une as duas ocorrências corresponderia, assim, à direção ("strike") do litossoma "varvito de Itu", com pequeno limite de erro, visto que a área de localização da sondagem é pequena, mesmo com as imprecisões ressaltadas.

Na sondagem São José n. ${ }^{\circ} 2$, a base do litossoma "varvito de Itu" encontra-

\footnotetext{
* Instituto Geológico - SMA - Caixa Postal 8772 - 01051 - São Paulo, SP - Brasil.
} 
se somente a $22 \mathrm{~m}$ do embasamento. Nas de Schincariol, devido às irregularidades do embasamento, ela se situa de 75 a $110 \mathrm{~m}$ acima do embasamento. NA IGIT $1 / 85$ localiza-se a $260 \mathrm{~m}$ acima do embasamento. Verifica-se, assim, uma situação normal de uma bacia de sedimentação gradativamente subsidente, ou seja, no sentido do mergulho das camadas quanto mais afastado um ponto se encontra da borda da bacia, maiores são as espessuras dos sedimentos abaixo de um determinado "datum" que neste caso é o topo do litossoma "varvito de Itu".

A sondagem São José n. ${ }^{\circ} 2$, após $2 \mathrm{~m}$ de solo, se inicia com o "varvito de Itu". Segundo a descrição do geólogo Carlos de Carvalho Torres (in MEZZALIRA, op. cit.), atravessou-se $30,30 \mathrm{~m}$ deste ritmito, em seguida $0,70 \mathrm{~m}$ de brecha intraformacional e, após, $2 \mathrm{~m}$ de ritmitos. Depois novamente $0,90 \mathrm{~m}$ de brecha intraformacional e outra vez $7,90 \mathrm{~m}$ de ritmitos. Abaixo ocorrem $0,40 \mathrm{~m}$ de argilito e siltito intercalados que podem ser interpretados como continuação do ritmito. Ter-se-ia, assim, $42 \mathrm{~m}$ de ritmitos, que estão sendo aqui interpretados como pertencentes ao litossoma "varvito de Itu".

\section{CONCLUSÕES}

No trabalho anterior (PETRI, 1985) foi estimada a extensão mínima do "lago varvito de Itu', em $8 \mathrm{~km}$ na direção E-W (dos afloramentos à sondagem Vila Real de Itu) e $4 \mathrm{~km}$ na direção N-S (dos afloramentos à sondagem IG-IT 1/85). A extensão do litossoma até a sondagem n. ${ }^{\circ} 2$ de São José daria uma distância de $9 \mathrm{~km}$ na direção $\mathrm{N}-\mathrm{S}$.

De acordo com ERNESTO (1977), ROCHA-CAMPOS \& SUNDARAM (1981) e ROCHA-CAMPOS et alii (1981), os ritmitos de Itu seriam varvitos verdadeiros, baseados nos seguintes argumentos: a) polens e esporos regularmente mais freqüentes nas camadas claras, correspondentes aos verões; b) variações paleomagnéticas compatíveis com as variações seculares atuais, de modo que os pares claro - escuros seriam anuais. Contudo, dadas as irregularidades de algumas camadas, podese supor que somente parte da rocha seria varvito strictu sensu.

Quanto à duração do "lago varvito de Itu', tem-se poucos dados para se chegar a uma avaliação fundamentada. LEINZ (1937) contou 300 varves em $1 \mathrm{~m}$ de varvito do Itararé, chegando a 4.500 anos para uma espessura de $15 \mathrm{~m}$. Para uma espessura de $45 \mathrm{~m}$, como, por exemplo, nas sondagens de Schincariol, terse-ia 13.500 anos. Este valor talvez seja excessivo visto que muitos pares de lâminas não representariam ciclos anuais, podendo, inclusive, ter duração menor. Em outras palavras, parte do ritmito poderia não ser varvito verdadeiro. ROCHA-CAMPOS et alii chegaram a uma idade de algumas centenas de anos para a duração desse lago, baseados na contagem de 260 pares claro - escuros da pedreira clássica de Itu. Como esta pedreira representa apenas parte da deposição no "lago varvito de Itu", a duração deste lago poderia se estender mais, talvez ultrapassando mil anos.

ROCHA-CAMPOS et alii (op. cit.) chamaram a atenção sobre a presença de granodecrescência ascendente a partir de um diamictito em contato com o embasamento cristalino, na região de Itu.

No poço da Estância Ituana ocorrem, segundo MEZZALIRA (1980), sobre o embasamento, arenitos conglomeráticos com concentração de seixos variados em tamanho e litologia e em vários níveis. Esta litologia poderia, talvez, corresponder a um diamictito.

Granodecrescência ascendente também se observa na sondagem IG-IT $1 / 85$, a partir de um diamictito em contato com o embasamento cristalino (Fig. 1). Estes sedimentos basais vão de $261,5 \mathrm{~m}$ a $233 \mathrm{~m}$.

O diamictito é maciço, de matriz arenosa e com seixos esparsos de litologias variadas passando, acima, para siltitos com intercalações finas e irregulares de arenitos médios e finos. O arenito, às vezes, se isola em bolsões dentro do siltito. Possivelmente águas de degelo, associadas, geneticamente, a geleiras não muito distantes do local, teriam formado o diamictito. Com a gradativa diminuição da energia da água, passar-se-ia a depositar os siltitos. O pequeno suprimento de areia proporcionaria a deposição das lentes e bolsões, acompanhando flutuações de energia da água.

O intervalo de 233 a $221 \mathrm{~m}$ é caracterizado por intercalações de diamictitos 
macicos e estratificados, ritmitos e folhelhos. A freqüencia de diastemas evidencia a instabilidade energética, com grandes flutuações de correntes.

A $233 \mathrm{~m}$ de profundidade ocorre um diastema que separa um arenito de granulação finà, abaixo, de um diamictito estratificado, acima. A superfície do diastema é irregular, com a estratificaçâo do diamictito se amoldando a ela!

10 A $232,5 \mathrm{~m}$ ocorre outro diastema separando diamictito maciço com seixos de litologias e formas variadas, muitos angulosos e facetados, situado abaixo do diastema, de um ritmito finamente laminado (presumivelmente um varvito), situado acima. A superfície é irregular e as lâminas do ritmito se amoldam a esta superfície inclusive acompanhando irregularidades causadas por seixos do diamictito que se projetam nesta superfície. As irregularidades da superfície do diastema são refletidas na disposição das lâminas do ritmito em espessura de, pelo menos, $8 \mathrm{~cm}$.

O intervalo de $221 \mathrm{~m}$ a $51 \mathrm{~m}$ é predominantemente arenoso, com grande freqüência de arcósios mal selecionados, passando para diamictitos maciços, arenosos, com esporádicos seixos centimétricos, comumente de granitos, e com finas intercalações síltico-argilosas e que se podem dispor ritmicamente com o arenito Estas intercalações sílticoargilosas tornam-se mais freqüentes a partir de $127 \mathrm{~m}$ para cima até $92 \mathrm{~m}$. Alguns destes pequenos ritmitos são formados por intercalações de siltito com arenito contendo pequenos seixos e grânulos, orientados paralelamente ao acamamento. Intercalações centimétricas de diamictito ocorrem entre $143 \mathrm{~m}$ e $145 \mathrm{~m}$, com freqüentes diastemas; os maiores seixos, centimétricos, são de siltito cinzento, de forma alongada, dispostos paralelamente ao acamamento. O siltito lembra os que ocorrem neste intervalo, intercalados em arenitos. Como o siltito é rocha pouco resistente, admite-se que ele provenha da própria seqüência deposicional, através de processos de canibalismo.

$\mathrm{O}$ diastema que ocorre a $145 \mathrm{~m}$ de profundidade exibe uma superfície com irregularidades da ordem de $5 \mathrm{~cm}$ de desnível entre as "cristas" e as "depressões". Ele separa um arenito muito fino, na base, de um diamictito arenoso com

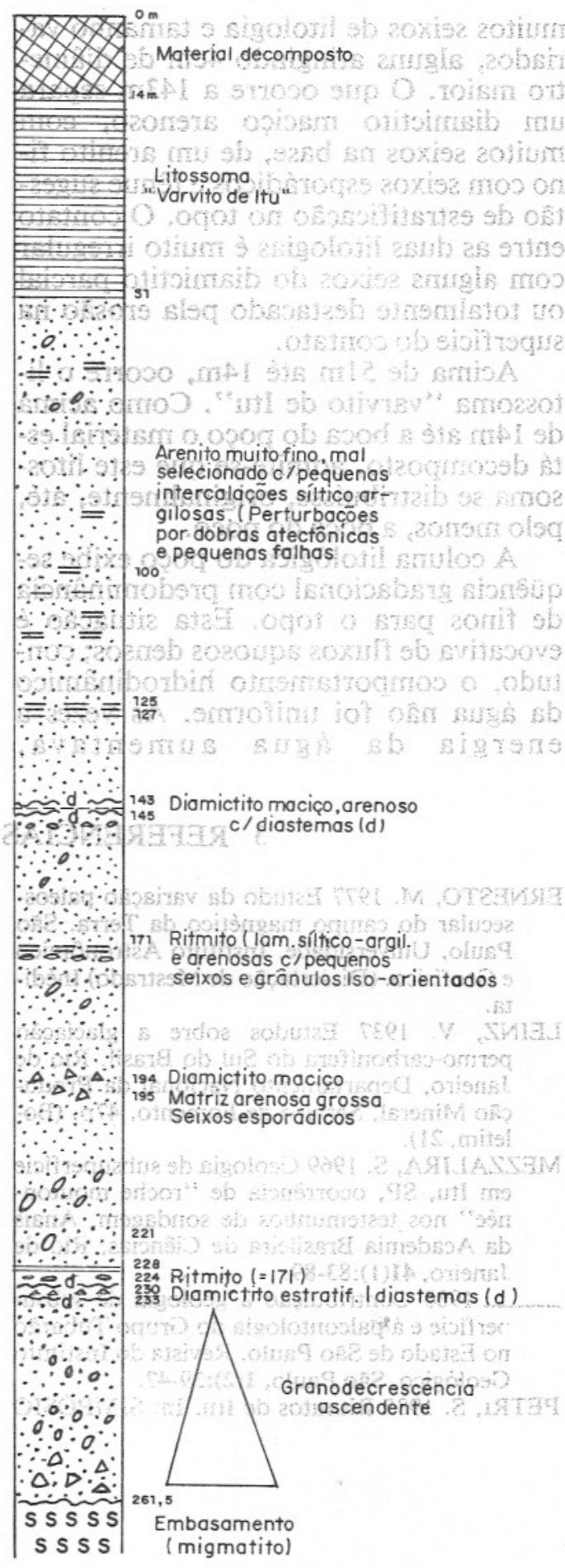

SONDAGEM I.G.- $1+1 / 85$

( Para localização em mapa-V-Petri, 1985) Cota da boca do poço : $515 \mathrm{~m}$

Coordenadas UTM

$\begin{array}{ll}\mathrm{Km} \mathrm{E} & \mathrm{Km} \mathrm{N} \\ 259,55 & 7428,70\end{array}$

DESCRIÇÃO: S.PETRI 
muitos seixos de litologia e tamanho variados, alguns atingindo $4 \mathrm{~cm}$ de diâmetro maior. O que ocorre a $143 \mathrm{~m}$ separa um diamictito maciço arenoso, com muitos seixos na base, de um arenito fino com seixos esporádicos e tênue sugestão de estratificação no topo. O contato entre as duas litologias é muito irregular com alguns seixos do diamictito parcial ou totalmente destacado pela erosão na superfície do contato.

Acima de $51 \mathrm{~m}$ até $14 \mathrm{~m}$, ocorre o litossoma "varvito de Itu". Como acima de $14 \mathrm{~m}$ até a boca do poço o material está decomposto, admite-se que este litossoma se distribuísse, originalmente, até, pelo menos, a boca do poço.

A coluna litológica do poço exibe seqüência gradacional com predominância de finos para o topo. Esta situação é evocativa de fluxos aquosos densos; contudo, o comportamento hidrodinâmico da água não foi uniforme. Às vezes a energia da água aumentava, depositando-se material mais grosseiro e culminando com erosão e desenvolvimento de diastemas. Outras vezes a queda de energia da água resultava em clásticos mais finos, talvez por represamento pela própria sedimentação, muito comuns nestas litologias. O "lago de Itu" seria um corpo de água represada de maior extensão e duração e como conseqüência de uma subsidência suave foi possível acumularem-se os varvitos e outros ritmitos globalmente chamados de "varvitos de Itu".

Influência direta glacial pode ter ocorrido na deposição do diamictito da base que eventualmente pode ser tilito. O restante da sedimentação, até a profundidade do poço de $51 \mathrm{~m}$, deve ter ocorrido em condições subaquosas, predominantemente de correntes. Acima de $51 \mathrm{~m}$ se instalou o ambiente lacustre. $\mathrm{Pa}$ ra toda a seqüência, contudo, há evidências da contribuição de gelo.

\section{REFERÊNCIAS BIBLIOGRÁFICAS}

ERNESTO, M. 1977 Estudo da variação paleossecular do campo magnético da Terra. São Paulo, Universidade, Instituto Astronômico e Geofísico. (Dissertação de Mestrado) Inédita.

LEINZ, V. 1937 Estudos sobre a glaciação permo-carbonífera do Sul do Brasil. Rio de Janeiro, Departamento Nacional da Produção Mineral, Serviço de Fomento. 47p. (Boletim, 21).

MEZZALIRA, S. 1969 Geologia de subsuperfície em Itu, SP, ocorrência de "roche moutonnée" nos testemunhos de sondagem. Anais da Academia Brasileira de Ciências, Rio de Janeiro, 41(1):83-89.

1980 Contribuição à geologia de subsu:erfície e à paleontologia do Grupo Tubarão no Estado de São Paulo. Revista do Instituto Geológico, São Paulo, 1(2):39-47.

PETRı, S. 1985 Ritmitos de Itu. In: SIMPÓSIO
REGIONAL DE GEOLOGIA、 5. ${ }^{\circ}$, São Paulo, 1985. Atas. São Paulo, Sociedade Brasileira de Geologia, Núcleo São Paulo. v.1 p.235-241.

ROCHA-CAMPOS, A. C. \& SUNDARAM, D. 1981 Geological and palynological observations on Late Paleozoic varvites from the Itarare 3ubgroup, Paraná Basin, Brazil. In: CONG IRESSO LATINO-AMERICANO DE PALEONTOLOGIA, 2. ${ }^{\circ}$, Porto Alegre, 1981. Anais. Porto Alegre, UFRGS. v.1 p. 257-275.

; ERNESTO, M.; SUNDARAM, D. 1981 Geological, palynological and paleomagnetic investigation on Late Paleozoic varvites from the Paraná Basin, Brazil. In: SIMPÓSIO REGIONAL DE GEOLOGIA, 3. ${ }^{\circ}$, Curitiba, 1981. Atas. Curitiba, Sociedade Brasileira de Geologia. v. 2 p.162-175. 